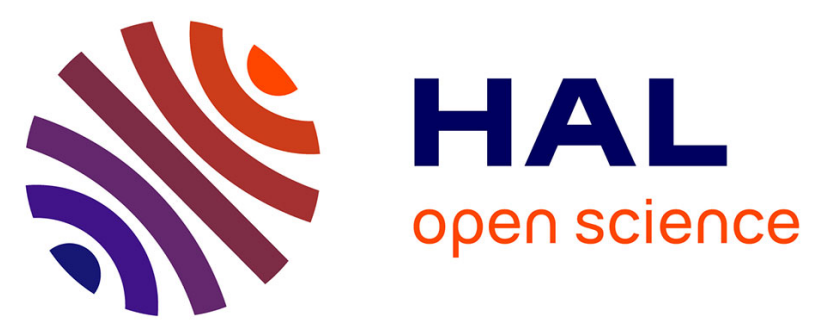

\title{
Variability of the Gulf Stream position and transport between 1992 and 1999: a re-analysis based on a data assimilation experiment
}

L. Berline, Charles-Emmanuel Testut, Jacques Verron, Pierre Brasseur

\section{- To cite this version:}

L. Berline, Charles-Emmanuel Testut, Jacques Verron, Pierre Brasseur. Variability of the Gulf Stream position and transport between 1992 and 1999: a re-analysis based on a data assimilation experiment. International Journal of Remote Sensing, 2006, 27, pp.417-432. 10.1080/01431160500254882 . hal00212268

\section{HAL Id: hal-00212268 \\ https://hal.science/hal-00212268}

Submitted on 14 Jan 2020

HAL is a multi-disciplinary open access archive for the deposit and dissemination of scientific research documents, whether they are published or not. The documents may come from teaching and research institutions in France or abroad, or from public or private research centers.
L'archive ouverte pluridisciplinaire HAL, est destinée au dépôt et à la diffusion de documents scientifiques de niveau recherche, publiés ou non, émanant des établissements d'enseignement et de recherche français ou étrangers, des laboratoires publics ou privés. 


\title{
Variability of the Gulf Stream position and transport between 1992 and 1999: a re-analysis based on a data assimilation experiment
}

\author{
L. BERLINE*†, C.-E. TESTUT†, P. BRASSEUR $\uparrow$ and J. VERRON† \\ †LEGI, UMR 5519 CNRS, BP 53X, 38041 Grenoble Cedex, France \\ $\$$ \$Mercator-Océan, 8/10 rue Hermes, Parc technologique du canal, 31526 Ramonville \\ Saint-Agne, France
}

\begin{abstract}
A multivariate dataset resulting from the assimilation of sea surface height and sea surface temperature data in an ocean circulation model of the North Atlantic, is used to study the Gulf Stream position variability from October 1992 to October 1999. The analysis takes place between $75^{\circ} \mathrm{W}$ and $50^{\circ} \mathrm{W}$ and focuses on two regions, west and east of $65^{\circ} \mathrm{W}$. By calculating zonal averages of the latitudinal position, a regular annual cycle of north-south oscillations of the Gulf Stream axis is identified in the eastern region, whereas inter-annual variations dominate in the western region. An empirical orthogonal function (EOF) analysis of space-time position anomalies reveals that, even though the annual cycle dominates over the whole domain, the variability has a spatial consistency within each individual region. The assimilation dataset is further used to analyse the variability of the Gulf Stream transport towards the east. Compared to the latitudinal position analysis, the characterization of the transport variability is more complex. Semi-annual fluctuations can be evidenced in both the regions; however, no significant correlation was found between the fluctuations of position and transport.
\end{abstract}

\section{Introduction}

The Gulf Stream (GS) system plays a specific dynamical role in the circulation of the North Atlantic Ocean. As a particularly intense nonlinear and unstable western boundary current, it mirrors much of the North Atlantic oceanic and atmospheric circulations (Visbeck et al. 2003). It also influences the circulation of the subtropical gyre and water mass distribution in the entire basin. Understanding its complex role, and its interactions with climate in particular, requires the study of its variability at various scales.

First, the GS dynamics can be characterized by transport characteristics. According to in situ observations, the overall transport of the GS is about $30 \mathrm{~Sv}$ through the Florida Straits, which then increases up to $93 \mathrm{~Sv}$ at $73^{\circ} \mathrm{N}$, and to $150 \mathrm{~Sv}$ at $55^{\circ} \mathrm{W}$ (Leaman et al. 1989, Hogg 1992). After Cape Hatteras $\left(75^{\circ} \mathrm{W}, 35^{\circ} \mathrm{N}\right)$, the current leaves the continental shelf and frees itself from bathymetric constraints: the flow widens, becomes less structured and also deeper. To explain the increase in transport downstream of Cape Hatteras, nonlinear recirculation theories have been proposed and validated in simple numerical models (Holland and Lin 1975, Käse and Krauss 1996). The main recirculation cells are the Northern Recirculation Gyre and, to the

\footnotetext{
*Corresponding author. Email: berline@hmg.inpg.fr
} 
south, the Worthington Gyre (Hall and Fofonoff 1993). More recently, the increase in transport has been attributed to the increase of velocity at depth (Johns et al. 1995). From in situ and satellite altimetry data, it has been suggested that the surface GS transport in several locations has a seasonal cycle. North-east of Cape Hatteras, surface transport estimated from the sea-surface height $(\mathrm{SSH})$ gradient exhibits a minimum in spring, coinciding with a southerly position of the flow, and a maximum during autumn corresponding to a northerly position of the current (Kelly and Gille 1990, Kelly 1991, Zlotnicki 1991). According to Hogg (1992) and Johns et al. (1995), this seasonal fluctuation in volume transport is limited to the upper $300 \mathrm{~m}$ and could be explained from the heating/expansion of surface waters. However, the total transport as estimated from current meters by Kelly et al. (1999) reaches a maximum in spring. In addition, according to Manning and Watts (1989), the seasonal cycle is more pronounced downstream of the New England Seamounts Chain (NESC), which runs in a NW-SE direction from $66^{\circ} \mathrm{W}$ to $60^{\circ} \mathrm{W}$.

At the same time, a number of studies have focused on the position of the GS. They first used in situ observations, then more recently altimetric and sea-surface temperature (SST) data. Analyses show, in particular, evidence of periodic behaviour and a certain spatial organization of fluctuations. Based on seven years of SST data, Lee and Cornillon (1995) distinguished two features in the variability of the GS position, one associated with along-current spatial variability (meanders) and the other with the overall variation in the flow's latitudinal position. Using an empirical orthogonal function (EOF) analysis, the authors identified a coherent southerly displacement of the current between $70^{\circ} \mathrm{W}$ and $60^{\circ} \mathrm{W}$ exhibiting a marked annual periodicity, whereas the variability in spatial structure has a periodicity of nine months. Based on four years of altimetric data, Kelly et al. (1999) found a marked seasonal variation in the GS mean latitudinal position and transport between $73^{\circ} \mathrm{W}$ and $64^{\circ} \mathrm{W}$. Using seven years of altimetric data, Frankignoul et al. (2001) observed very little seasonal variability in the GS position compared to interannual variability. However, they observed a latitudinal in-phase displacement from $75^{\circ} \mathrm{W}$ to $50^{\circ} \mathrm{W}$. Similarly, using 30 years of data from various origins, Taylor and Stephens (1998) found no significant seasonal variability in the $79^{\circ} \mathrm{W}-65^{\circ} \mathrm{W}$ segment. Finally, the conclusions of the literature regarding the mode of variability in the GS position are diverse. This can be explained by the different datasets used, the areas of interest, and the method used to determine the position of the GS and to analyse the variability.

As far as the GS position is concerned, the issue of the variability mode - seasonal or inter-annual - is still not settled, while for GS transport, our knowledge about variability in amplitude and spatio-temporal structure remains poor, so that the question is even more open. The objective of the present work is to describe and analyse temporal and spatial variability in the position and transport of the GS from a regional perspective. Its particularity is due to the nature of the data used: these consist of 10-day forecasts, obtained from numerical simulations with assimilation of SST and SSH in an eddy-permitting model of the North Atlantic Ocean. The assimilation process synthesizes the information distributed in time and space that is contained in the model physics and the surface observations. It results in a coherent set of dynamical and thermodynamical data, with a fairly good time and space resolution. Compared to sea-surface observations, our dataset has the advantage of a three-dimensional (3D) regular distribution and the disadvantage of being less accurate at observation points since the assimilated data are weighted according to 
the model/data relative errors. Compared to the free model, it has the advantage of providing more reliable results, in spite of residual imperfections of the model and the assimilation method. A validation study can be found in Testut et al. (2003).

In the present study, the GS position is computed from the simulated temperature and SSH data fields between $75^{\circ} \mathrm{W}$ and $50^{\circ} \mathrm{W}$. To analyse lateral variations of the GS axis, indexes of latitudinal position were computed at the scale of the domain first, and then in two distinct areas separated by the NESC (east and west of $65^{\circ} \mathrm{W}$ ), following several authors who mentioned the influence of the NESC on the regional character of the GS mean path and meandering (Richardson 1981, Cornillon 1986, Ezer 1994). To analyse the consistency of displacement, we extracted the dominant modes of fluctuations in position in a similar manner to that used by Lee and Cornillon (1995), Kelly (1991) and Frankignoul et al. (2001). A regional analysis was conducted to examine the question of upstream and downstream differences in greater detail. Finally, the GS transport was computed using meridional sections from $75^{\circ} \mathrm{W}$ to $50^{\circ} \mathrm{W}$. Transport variability was also examined, in addition to the relationship between position and transport.

In $\S 2$, the dataset is presented as well as the methodologies used for defining the GS position and calculating the GS transport. Diagnostics of the computations are presented in $\S 3$ and $\S 4$. Finally, the conclusions are presented in $\S 5$.

\section{Data fields}

\subsection{Numerical simulation}

The physical model used for the numerical simulation is the ocean primitive equation OPA model, version 8.1 (Madec et al. 1998). This model has a geopotential vertical coordinate and assumes the rigid lid approximation at the ocean surface. The horizontal resolution is $1 / 3^{\circ}$ in longitude and $1 / 3^{\circ} \cos (\varphi)$ in latitude (i.e. $28 \mathrm{~km}$ at $\left.40^{\circ} \mathrm{N}\right)$. On the vertical, the numerical grid includes 43 levels. The computational domain covers the North Atlantic from $20^{\circ} \mathrm{S}$ to $70^{\circ} \mathrm{N}$ latitude, and from $98.3^{\circ} \mathrm{W}$ to $20.6^{\circ} \mathrm{E}$ longitude. The forcing fields (heat fluxes and winds) are derived from a reanalysis of European Center for Medium range Weather Forecasts (ECMWF) 6-h forecasts. SST is restored to the Reynolds weekly analysis, while sea-surface salinity is relaxed to the Levitus monthly climatology.

The assimilated data consist of gridded products available every 10 days at $1 / 4^{\circ}$ resolution: SSH maps were computed using sea-level anomalies measured by the Topex/Poseidon (T/P) and European Remote Sensing (ERS) satellites and a prior estimate of the mean SSH, while SST maps were obtained from infrared imagery (Advanced Very High Resolution Radiometer (AVHRR) instrument, Pathfinder mission). The data assimilation technique is the sequential SEEK filter (Singular Evolutive Extended Kalman filter, Pham et al. 1998). Every 10 days, a 3D analysis state vector is computed, which is an optimal compromise (in the Kalman filter sense) between the (3D) forecast state vector from the model and the (surface) observations. Optimality is based on data/model weighting using the respective estimated errors. Starting from this analysis state vector, the model is re-initialized for a new 10-day simulation sequence.

Testut et al. (2003) performed a seven-year hindcast of the period October 1992 to October 1999 with the assimilation system described above, showing a quite realistic representation of the mid-latitude North Atlantic circulation at $1 / 3^{\circ}$. The position of the surface currents and their transport are considerably improved by comparison 
with the free simulation. The levels and distribution of eddy kinetic energy as well as the position of the GS are in good agreement with the classical picture of the North Atlantic circulation. Comparisons with independent Expandable Bathythermograph (XBT) data in the GS region show that the assimilation solution reduces up to $30 \%$ of the misfits to the vertical profiles, thus making the temperature fields more consistent with in situ measurements.

Every 10 days during the 1992-1999 period, the assimilation system delivers analyses and 10-day forecasts of the 3D ocean state discretized on the model grid. The simulation data used in this work are the temperature, velocity and SSH fields extracted in the GS sector from the 10-day forecasts. Compared to the analysis states, the forecasts are better suited to explore the dynamical properties of the flow because the physical variables have been dynamically adjusted by the model and forcing conditions. It is worth noting that the diagnostics discussed below were repeated also with monthly averages of the 10-day forecasts, but no significant differences were observed in the results.

\subsection{Extraction and diagnostics of the GS latitudinal position}

In order to properly analyse the variability of the GS, a conventional approach must be adopted to characterize the latitudinal position of the current axis from the numerical datasets. Several definitions are given in the literature, depending on the data type. When using velocity data, the position of the core of the current can be identified by the continuous set of locations where velocity reaches a maximum. As for altimetric data, the surface position of the current in the geostrophic approximation corresponds to the point where the SSH reaches its maximum gradient. From temperature data, the position of the northern front of the jet (separating the warm GS waters from the cold waters of the Labrador current) can be defined by the $15^{\circ}$ or $17^{\circ} \mathrm{C}$ isotherm at $200 \mathrm{~m}$.

A strong point of this numerical study lies in the possibility to diagnose the GS position jointly from temperature and SSH fields, as they are complementary to each other: the model SSH gives a surface position that is fairly representative of the mesoscale circulation, while the temperature fields provide a subsurface view of the current's position that results from the dynamics and thermodynamics of the assimilated model.

Based on the simulation results, the $15^{\circ} \mathrm{C}$ isotherm at $200 \mathrm{~m}$ was selected to identify the GS position from the temperature field, while the $-0.2 \mathrm{~m} \mathrm{SSH}$ isocontour was found to best coincide with the position of the maximum gradient in the rise of the sea surface. Then we applied a method to extract continuous isocontours, providing an ensemble of 256 instantaneous GS trajectories from the 10-day forecast series. As the core of the current is between $100 \mathrm{~km}$ and $200 \mathrm{~km}$ wide, there is a shift in latitude between the position of the core of the current (determined by SSH data) and its northern boundary (determined by temperature data).

In order to estimate the main trends of the GS variability region by region and the possible impact of the NESC, it is necessary to filter the local fluctuations due to the meandering of the jet. Mean latitudinal positions are therefore calculated by zonally averaging the position indexes over a distance that is at least greater than the wave length of the meanders (estimated at $420 \mathrm{~km}$ by Lee and Cornillon 1995). Such averages are calculated separately in the so-called 'upstream' $\left(75^{\circ} \mathrm{W}-65^{\circ} \mathrm{W}\right)$ and 'downstream' $\left(65^{\circ} \mathrm{W}-50^{\circ} \mathrm{W}\right)$ regions. 
Finally, EOF analyses of the fluctuations in position with respect to the mean trajectory are performed, which make it possible to characterize the spatial organization and consistency of the latitudinal variations over the study area.

\subsection{Extraction and diagnostics of the GS transport}

In the real world, as in the simulation output, defining the actual transport of the GS is complicated by the need to identify the waters that belong to the GS and those belonging to recirculations or eddies detached from the main stream. At a resolution of $1 / 3^{\circ}$, the core of the current is discretized over only three or four grid points in a meridional section. As a first approximation, it is justified to consider that only the water that moves towards the east must be accounted in the transport estimates. We therefore define the transport of the GS as the integral on a meridian section of the positive zonal component of the velocity $(u)$. Within each meridian section, the calculation is limited to the first $1000 \mathrm{~m}$, i.e. the surface layer where the core of the current is confined. In addition, the meridian sections must be limited laterally. As shown by figure 1, which represents the mean SSH of the 10-day forecasts, permanent recirculations on both sides of the current can locally modify the transport estimates. Thus, the section limits are set as shown by figure 1 in such a way as to incorporate the envelope of the GS positions and to take these recirculations into account.

The transport is calculated through each of the north-south sections of the GS area (that is every $30 \mathrm{~km}$ ) between $74.5^{\circ} \mathrm{W}$ and $50^{\circ} \mathrm{W}$, representing a total of 73 sections. As with the position, regional averages of the transport are calculated in the upstream and downstream regions.

\section{Analysis of the GS trajectories}

\subsection{Ensemble mean position and spread}

Figure 2 shows the ensemble mean of the latitudinal position of the GS trajectories. The average position derived from the model SSH shows good overall consistency

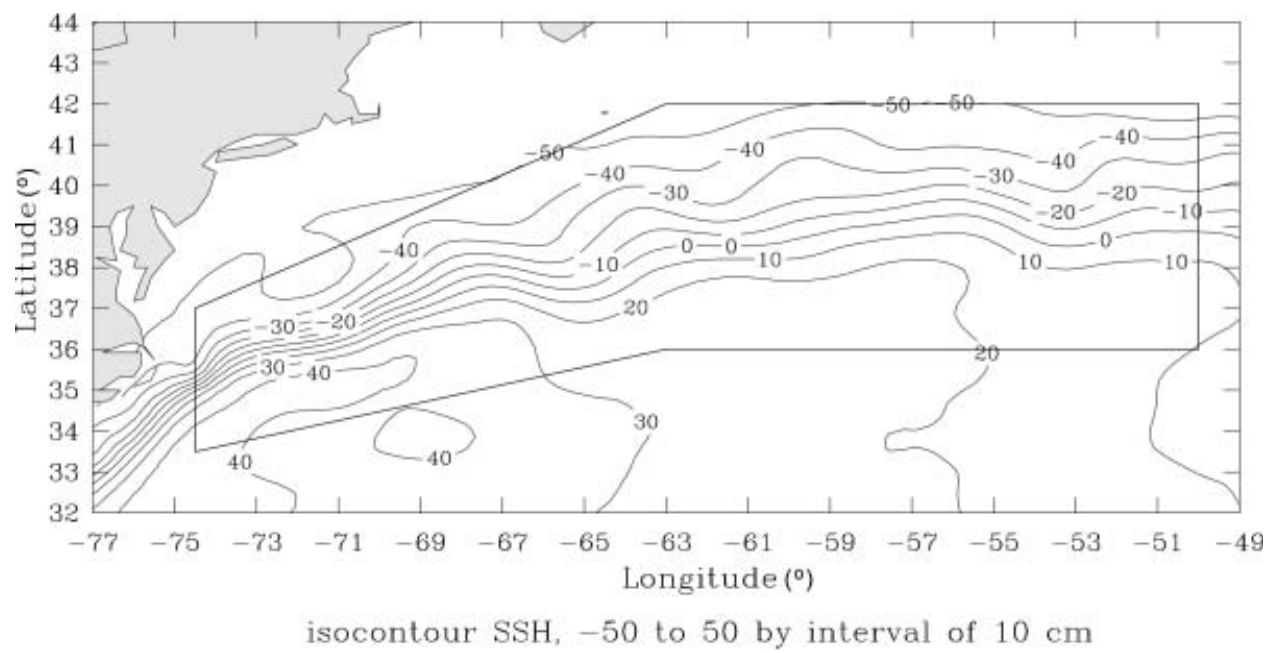

Figure 1. Mean sea-surface height (in cm) of the period October 1992 to October 1999; the solid box indicates the northern and southern bounds used to compute the zonal transport of the Gulf Stream. 


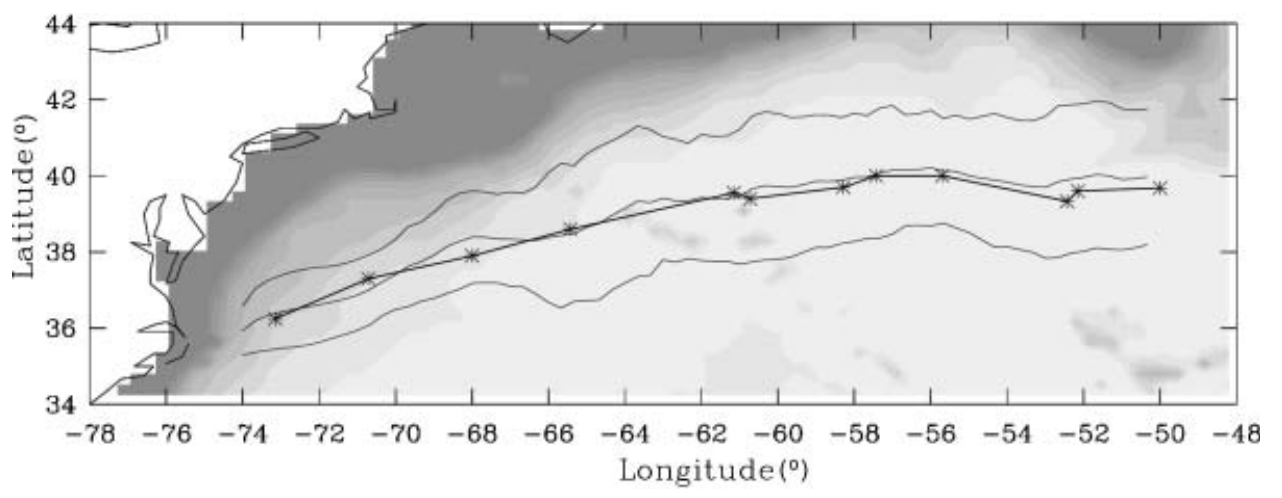

Figure 2. Mean position and envelope at two standard deviations (thin solid lines) of the Gulf Stream latitudinal positions calculated from the hindcast experiment; the mean GS axis obtained by Frankignoul et al. (2001) is shown by the solid curve with stars; the model bathymetry is represented in greyscale, showing the shelf break and the New England Seamounts Chain.

with that calculated by Frankignoul et al. (2001), based on T/P altimetric data obtained during the period October 1992 to November 1998. However, some differences can be observed, namely around $68^{\circ} \mathrm{W}$ and after $53^{\circ} \mathrm{W}$. The time lag between the observation period and the period described by our numerical data, as well as the overall assimilation process, could explain these differences.

The standard deviation of the positions calculated from the ensemble as a function of longitude reflects the spread of the GS trajectories. The two standard deviations envelope indicates considerable temporal variability in latitudinal position, reaching about $2^{\circ}$ along a north-south axis (figure 2 ). This variability is comparable to that estimated by Frankignoul et al. (2001).

The lateral spread can be attributed to the occurrence of transient meanders, and also to meridional shifts of the current at larger scales. The amplitude of the lateral excursions increases significantly to the east of $67^{\circ} \mathrm{W}$, and then remains relatively constant. This change in behaviour coincides with the passage of the current over the NESC, which is able to modify the development of meanders according to Richardson (1981) and Cornillon (1986). One can also notice that the flow of the GS is slightly deflected towards the south at $56^{\circ} \mathrm{W}$.

\subsection{Temporal variability in the upstream and downstream zones}

In order to separate the overall latitudinal movement of the current and the local effects of meanders, a necessary first step involves determining the temporal variability of the mean latitudinal position in the upstream and downstream zones.

The time series of zonally averaged positions obtained from $\mathrm{SSH}$ and temperature data are represented in figure 3 . The range of lateral excursions increases from $1.7^{\circ}$ in the upstream zone to $2.3^{\circ}$ in the downstream zone, consistently with the spread of the ensemble envelope shown in figure 2. Upstream, the two curves exhibit fluctuations at various time scales. From these raw time series, however, it is unclear whether intra-annual or inter-annual variations dominate. Downstream, the time series reflect variations with annual periodicity more clearly, with the GS axis reaching its most southerly position in the spring and most northerly position in autumn, though the position determined by temperature exhibits a more complex behaviour than that obtained with SSH. 
(a)

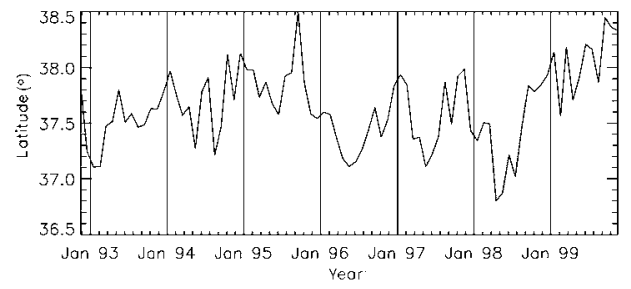

$(c)$

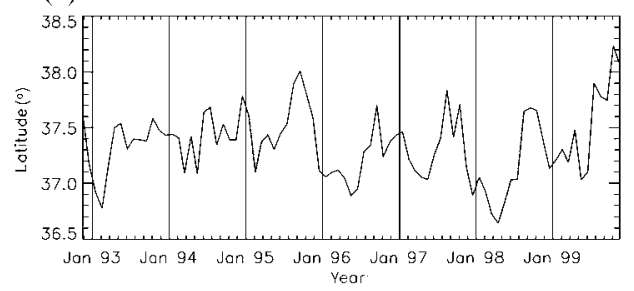

(b)

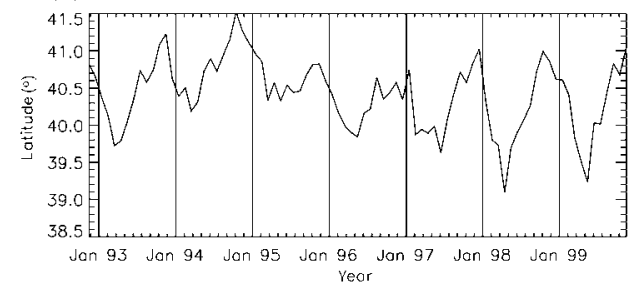

(d)

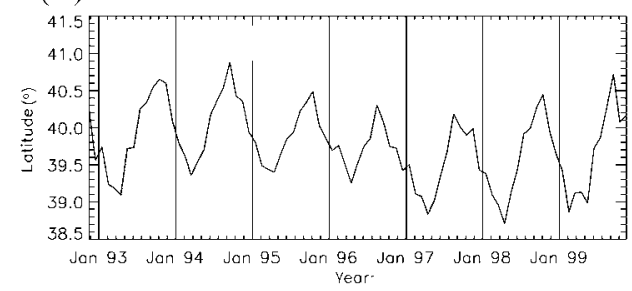

Figure 3. Time evolution of the latitudinal position of the Gulf Stream axis, averaged between $75^{\circ} \mathrm{W}$ and $65^{\circ} \mathrm{W}\left(a\right.$ and $c$ ) and between $65^{\circ} \mathrm{W}$ and $50^{\circ} \mathrm{W}(b$ and $d$ ), calculated from the $200 \mathrm{~m}$ temperature $(a$ and $b)$ and $\operatorname{SSH}(c$ and $d$ ) data.

A comparison of the variations in position obtained from $\mathrm{SSH}$ and from the $15^{\circ} \mathrm{C}$ isotherm provides insights into the consistency between the surface and subsurface flow at a depth of $200 \mathrm{~m}$. Overall, these variations are quite similar in amplitude and phase, which suggests a relatively coherent vertical structure from the surface to a depth of $200 \mathrm{~m}$.

In order to further analyse the time scales at work and distinguish between seasonal and inter-annual fluctuations, the mean annual cycle of the 1993-1999 period is extracted from the time series (figure 4). The amplitude of the seasonal cycle is $0.55^{\circ}$ in the upstream zone and becomes larger than $1.0^{\circ}$ in the downstream zone, indicating that the seasonal nature of the signal intensifies to the east of the NESC.

In the upstream zone, the amplitude and phase obtained from SSH and temperature data are comparable, with a minimum occurring in May and a maximum in October. In the downstream zone, the amplitude of the surface variations from SSH appear slightly larger $\left(\sim 1.25^{\circ}\right)$ than that observed at $200 \mathrm{~m}$ from temperature $\left(\sim 1.1^{\circ}\right)$, consistently with the study by Rossby and Benway (2000). The extreme positions are reached on average in April (south) and September (north) for the SSH, and in November (north) for temperature. This time lag in reaching the northerly position between the SSH and temperature can also be observed by comparing the results of Kelly et al. (1999) using altimetric data and Cornillon (1986) using SST data.

The distinct upstream and downstream behaviour, with an intensified seasonal cycle downstream, provides a new vision of the GS variability by comparison with Kelly et al. (1999), who noted a stronger seasonality upstream. These results also differ from those obtained by Frankignoul et al. (2001), who found seasonal variability to be non-significant over the zone as a whole. For the position determined by SST, Lee and Cornillon (1995) did not make any distinction between upstream and downstream zones in their analysis.

Finally, to compare the inter-annual variations observed in each zone, the mean annual cycle was removed from the time series of figure 3 . Figure 5 shows the 


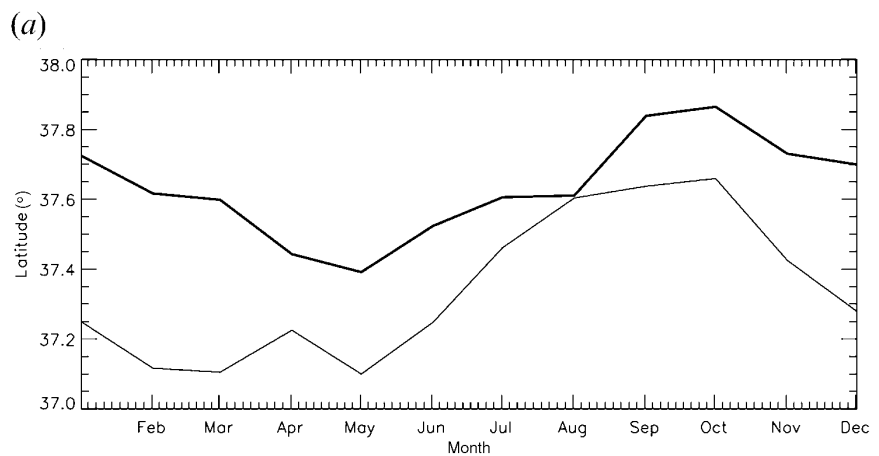

(b)

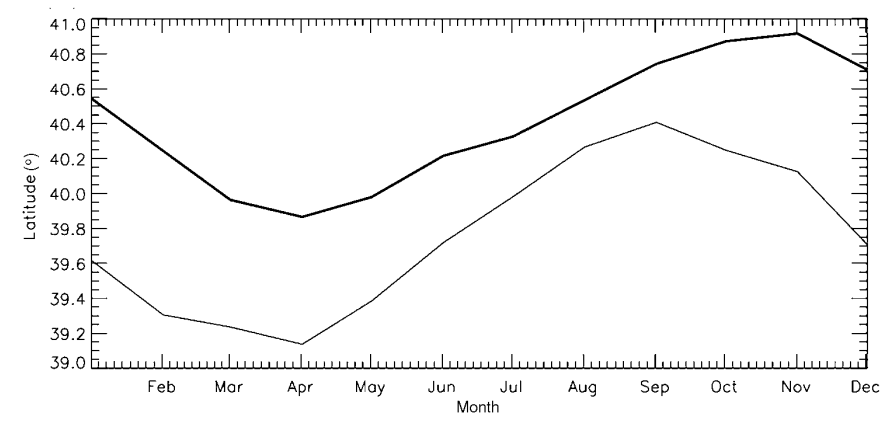

Figure 4. Monthly average of the Gulf Stream latitudinal positions, computed between $75^{\circ} \mathrm{W}$ and $65^{\circ} \mathrm{W}(a)$, and between $65^{\circ} \mathrm{W}$ and $50^{\circ} \mathrm{W}(b)$. The thick line shows the position calculated from the $200 \mathrm{~m}$ temperature data, and the thin line shows the position calculated from the SSH data.

de-seasonalized time series, in addition to a moving average of these calculated with a six-month window. The upstream and downstream low frequency signals exhibit differences, but the range of inter-annual variations is about $0.6^{\circ}$ from the $\mathrm{SSH}$ data, and $0.9^{\circ}$ from the temperature data in both zones. During the seven-year period, one can distinguish three phases: a first period with a trend towards the north, then an inversion with a southerly trend, and then a northerly trend again. The most southerly position is reached during winter 1997/1998. The downstream signal has a single peak (end of 1994), while upstream there are three (beginning of 1995, 1997 and in 1999).

From figures 2-5, one can conclude that the lateral excursions of the GS axis occur at both seasonal and inter-annual time scales. In the upstream zone, the low frequency signal slightly dominates the seasonal cycle, while downstream the seasonal fluctuations are more intense and dominate the inter-annual variations. These results provide an a posteriori justification for making a distinction between upstream and downstream regions.

Since the general behaviour of the GS position variability differs in the two zones, we will examine in the following section whether a spatial organization of the variations can be identified on the entire domain or within the regions.

\subsection{Spatial modes of variability}

To analyse the spatial organization of latitudinal oscillations in the GS sector and the correlations between the variations at different longitudes, the covariance matrix 

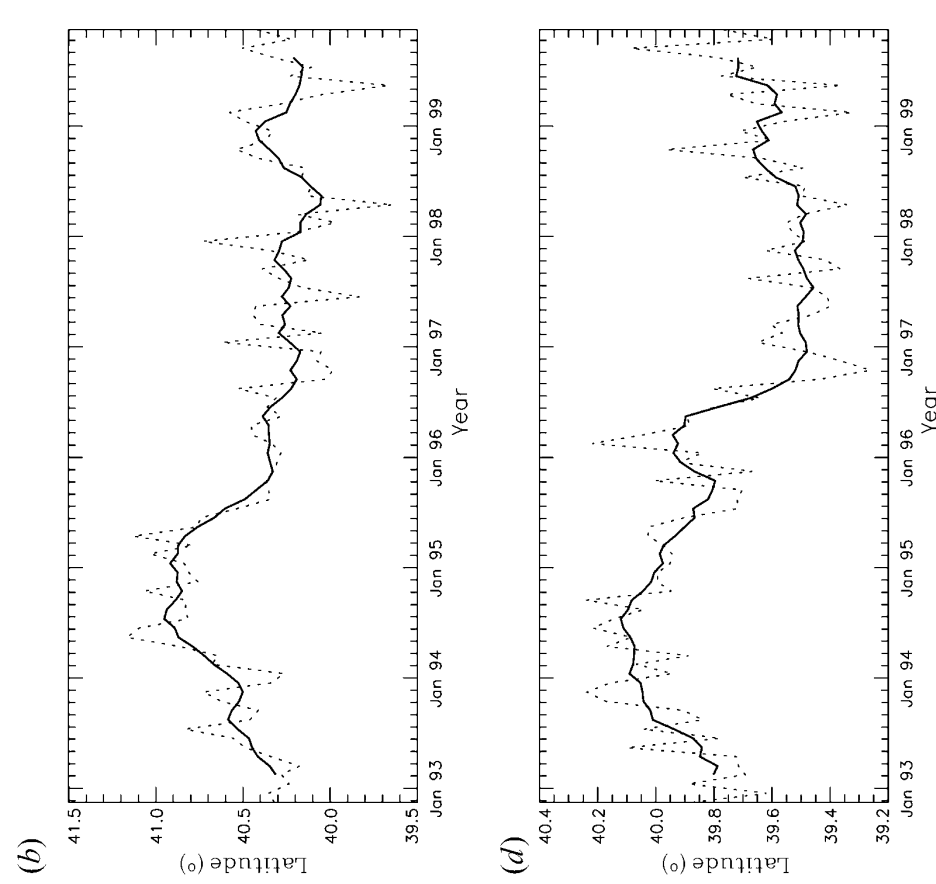

름

30

政

苋苛

홈

苛

तु

胥

हี

究品

岂苛

0

$\stackrel{00}{=}$

등

$s$

(о) әрnา!ฺр
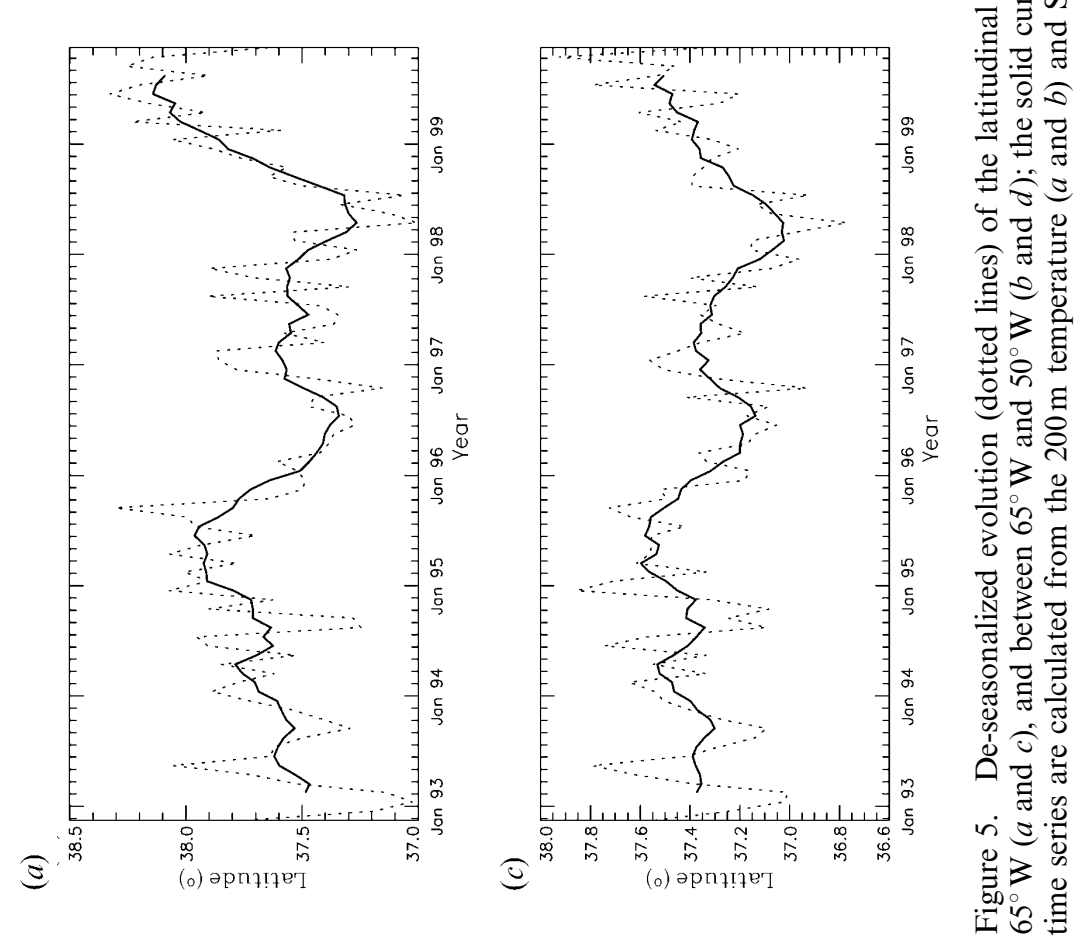
of normalized latitudinal fluctuations around the ensemble mean trajectory was decomposed into empirical orthogonal functions (EOFs). The latitudinal position is known for 73 longitudes $\left(1 / 3^{\circ}\right.$ grid between $74.5^{\circ} \mathrm{W}$ and $\left.50^{\circ} \mathrm{W}\right)$, leading to a decomposition into 72 spatial modes and associated principal components as a function of time.

The diagnostics presented are those calculated from the position data obtained from SSH: the results with the temperature data are similar and are not shown. The first two dominant EOFs can be considered as statistically significant, and can help in explaining the nature of the GS lateral displacements (figure 6). The first EOF, which explains $30.0 \%$ of the total variance of the ensemble, represents a coherent latitudinal shift over the domain, with an amplitude that increases to the east of $66^{\circ} \mathrm{W}$. The second EOF, which explains only $10 \%$ of the total variance, indicates a possible inflection of the current at $56^{\circ} \mathrm{W}$.

The principal component associated with the first EOF shows a very marked annual periodicity, depicting a similar behaviour to that of the downstream position calculated earlier but with the additional information of consistent motion over the whole domain. It is consistent with the results obtained by Lee and Cornillon (1995) using surface temperature data.

The interpretation of the second principal component is less easy, though it shows a trend similar to the inter-annual signal of figure 5. An inversion is observed, which begins in autumn 1995 and lasts about eight months, consistently with the latitudinal shift to the south which takes place in figure 5 at the beginning of 1996. A sudden shift towards the south is also noted by Frankignoul et al. (2001) at the same time.

To analyse the spatial consistency of fluctuations within the two regions, the EOF analysis was repeated separately on the upstream and downstream zones. Figure 7 shows the first EOFs and principal components in both regions, which represent $34 \%$ and $36 \%$ of the total variance respectively. The dominant mode of variability exhibit a consistent latitudinal shift in the two regions.

(a)

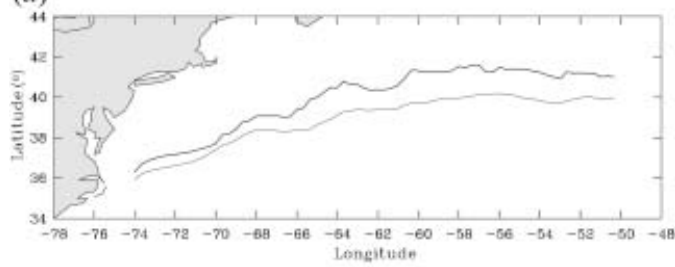

(c)

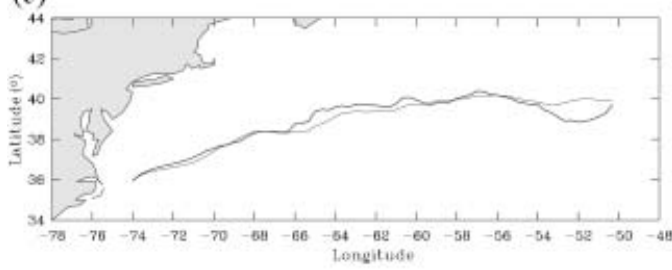

(b)

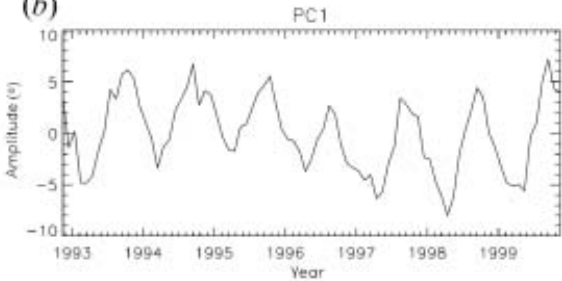

$(d)$

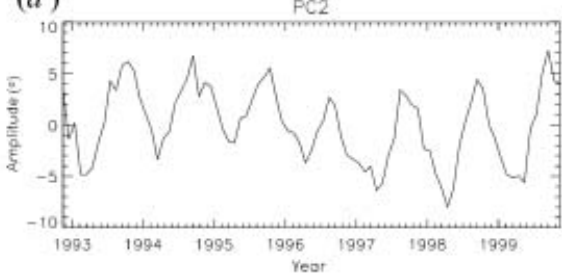

Figure 6. EOF analysis of the Gulf Stream trajectories calculated over the region between $75^{\circ} \mathrm{W}$ and $50^{\circ} \mathrm{W}$ : $(a$ and $b$ ) the first mode and associated principal component, which accounts for $30 \%$ of the ensemble variance; $(c$ and $d$ ) the second mode and associated principal component, which accounts for $10.1 \%$ of the ensemble variance. Each EOF is plotted in order to represent typical lateral displacements of the position. 

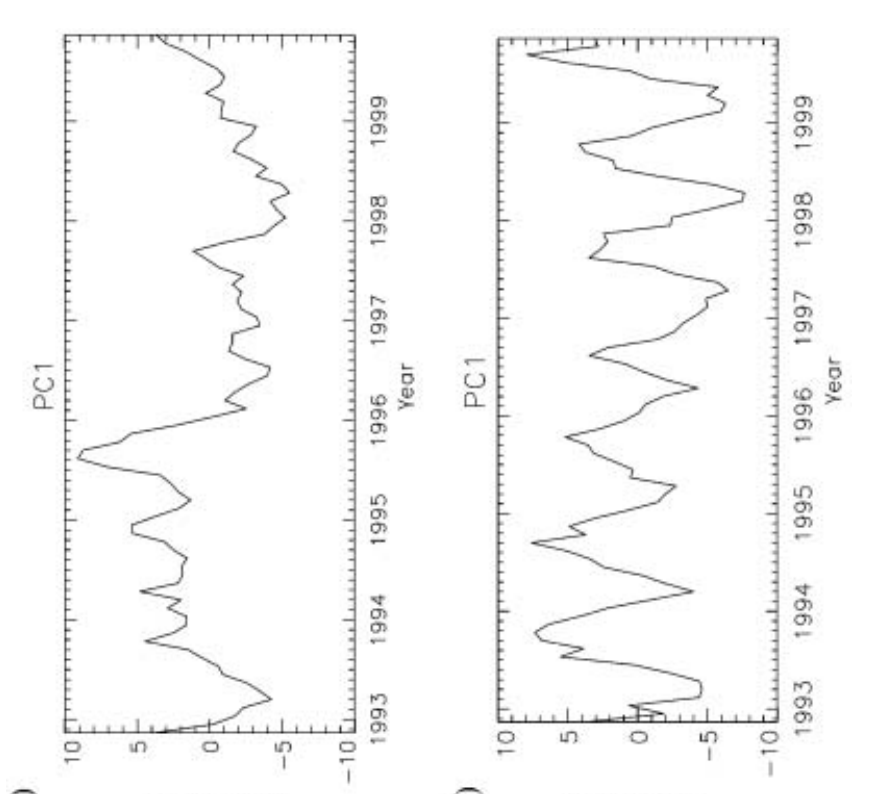

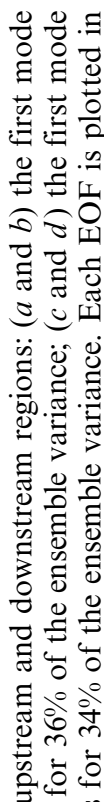

s

छ

(o) әpny!ldwy
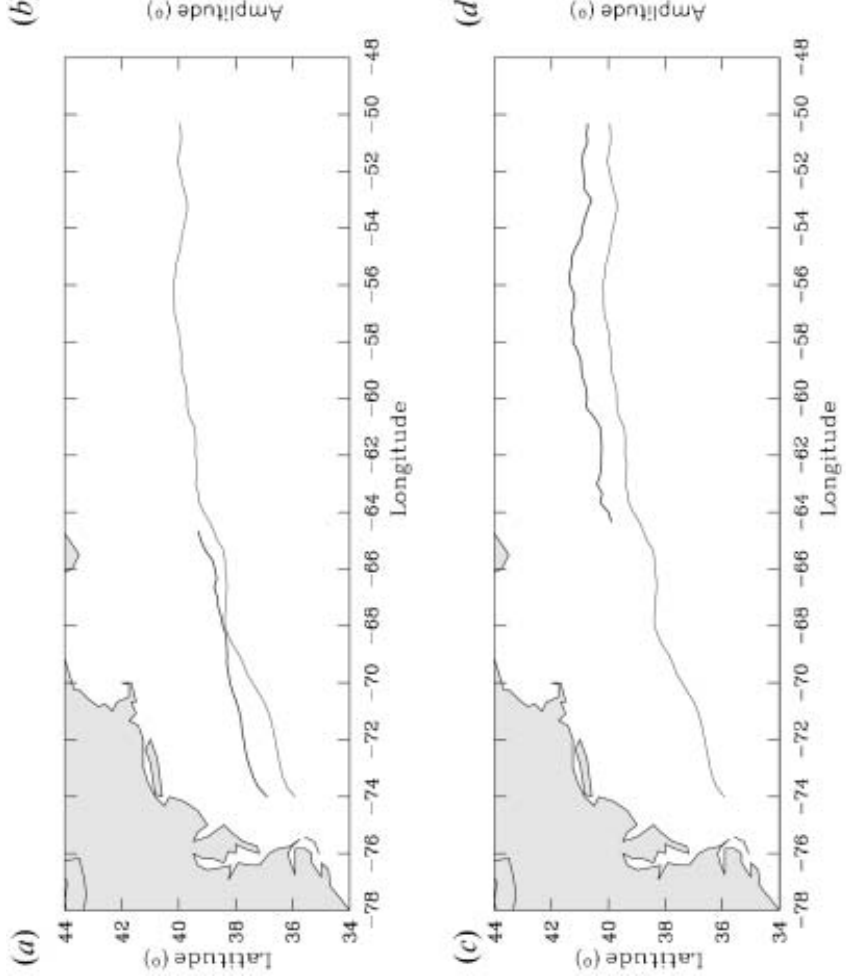

导节

: 00

롱

艼 을

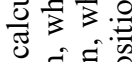

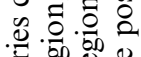

可过

过

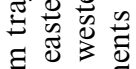

屯ิ

涪. $\Xi$

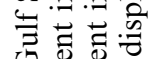

은 융

渮 홍

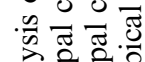

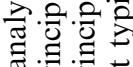

흘

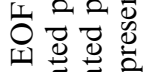

$\therefore \cdot \frac{\pi}{0} \cdot \frac{\pi}{0}$

대용

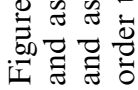


The principal components differ, however, with respect to their temporal behaviour. Upstream, periodicity at intra-annual and inter-annual time scales may be observed, while a distinct seasonal cycle occurs downstream. A comparison with the time series of figures 3 and 5 confirms the idea that seasonal variability dominates downstream, while inter-annual variability dominates upstream. In addition, the consistency at basin scale and then within both zones suggests that the source of variability is mainly associated to large-scale phenomena rather than to local perturbations.

In the following section, the variations in transport observed along the current will be examined using the same approach as that used for position.

\section{Analysis of the GS transport}

The transport of the GS is computed for each meridional sections between $74.5^{\circ} \mathrm{W}$ and $50^{\circ} \mathrm{W}$ according to the methodology presented in $\$ 2$, leading to 73 time series. As for the GS trajectories, we will examine the temporal mean and variability in the two areas.

\subsection{Mean GS transport and standard deviation}

The mean transport values calculated according to longitude (figure 8) are consistent with those reported in the literature (Hendry 1988, Leaman et al. 1989). A total transport of $60 \mathrm{~Sv}$ is estimated near Cape Hatteras. From $74.5^{\circ} \mathrm{W}$ to $70^{\circ} \mathrm{W}$, the transport doubles with a rate of increase of $15 \mathrm{~Sv}$ per $100 \mathrm{~km}$. This strong increase is due to the interaction of the main current with the recirculations. Figure 1 clearly shows the northern recirculation centred on average on $38^{\circ} \mathrm{N} 72^{\circ} \mathrm{W}$, and the southern recirculation centred on $34^{\circ} \mathrm{N} 69^{\circ} \mathrm{W}$. The first maximum of $130 \mathrm{~Sv}$ is observed at $69.5^{\circ} \mathrm{W}$. Transport values then decrease rapidly until longitude $67.5^{\circ} \mathrm{W}$, reaching $100 \mathrm{~Sv}$. This can be explained by the loss of water masses from the southern recirculation. After, transport values increase again, with an average rate of increase of about $3 \mathrm{~Sv}$ per $100 \mathrm{~km}$, until a maximum of $150 \mathrm{~Sv}$, near $55^{\circ} \mathrm{W}$. Then a strong decrease is noted, related to the existence of a recirculation to the south.

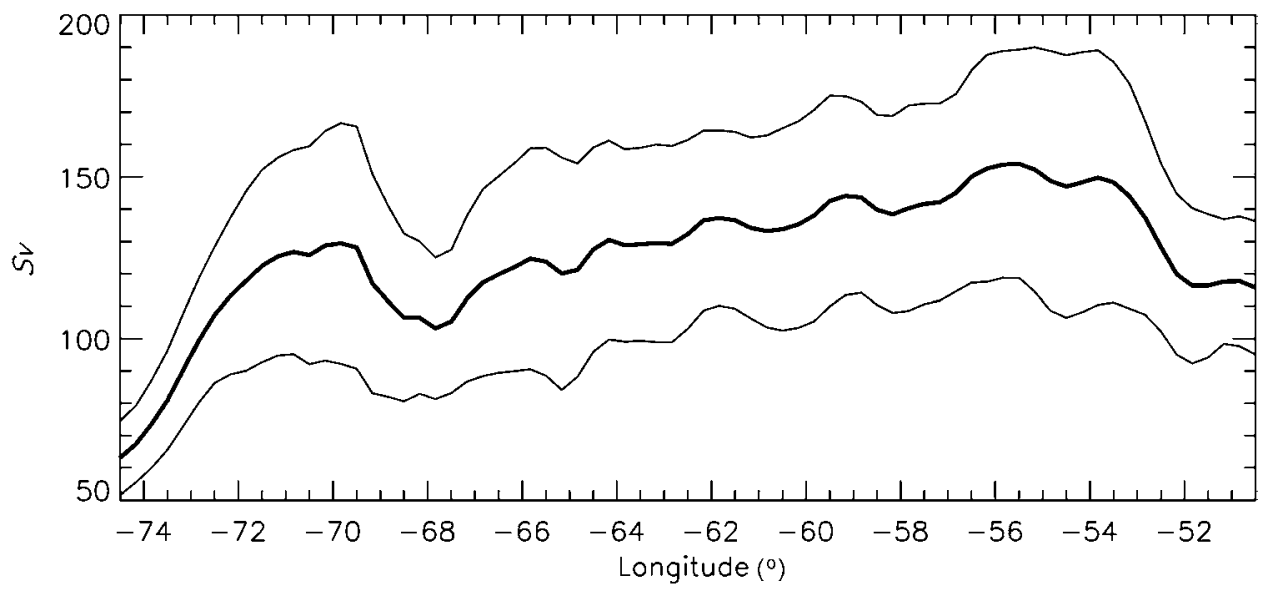

Figure 8. Time mean (thick line) and two standard deviation envelope (thin line) of the Gulf Stream transport calculated from the hindcast experiment as a function of longitude. 
The standard deviation of the transport values (from 10 to $40 \mathrm{~Sv}$ ) is relatively high compared to estimates found in the literature. This can be explained by the high frequency variability of the velocity fluctuations in the model, and also by the width of the calculation sections which may incorporate intermittent mesoscale features and transient recirculations close to the core of the current.

\subsection{Temporal variability in the upstream and downstream zones}

The zonal mean transport is calculated in the upstream and downstream zones in the same way as for latitudinal position, with the aim to possibly distinguish annual variations and inter-annual fluctuations. The original GS transport time series are shown in figure $9(a)$ together with the time series with the annual cycle removed (figure $9(b)$ ).

The GS transport exhibits fluctuations at various time scales, without any clear periodicity in the variations. Strong fluctuations exist over periods ranging from a few months to several years even after removing the mean annual cycle. Moreover, an EOF analysis was unable to detect any significant correlations between the upstream and downstream variations, even with a time lag. Sturges and Hong (2001) also showed considerable variability in measurements taken for two sections that are closely located ( $200 \mathrm{~km}$ distance). In summary, the variability in the GS transport appears to be fairly complex, and this can possibly be explained by the impact of Rossby waves and mesoscale eddies on the local GS transport.

Concerning the mean annual cycle, two distinct features appear. Firstly, the annual variations seem to be of larger amplitude in the downstream zone compared to upstream. The range of annual variations is about $30 \mathrm{~Sv}$ downstream, which is high compared with the values of 10-16 Sv suggested by Manning and Watts (1989) and Sato and Rossby (1995). This property reinforces the seasonal character of the GS variability evidenced in the downstream zone from the analysis of the GS trajectories.

Secondly, the transport exhibits two maxima, in June-July and in DecemberJanuary, separated by two minima, at the end of the winter (February-March) and in autumn (September-November). Therefore, the cycle suggests a semi-annual periodicity. With a dataset limited to the north-eastern region off Cape Hatteras, Fu et al. (1987) also noted two peaks. By contrast, the annual cycle observed by Kelly et al. (1999) from altimetric data is unimodal, with a maximum in autumn and a minimum in spring corresponding to the lateral excursions of the GS position.

(a)

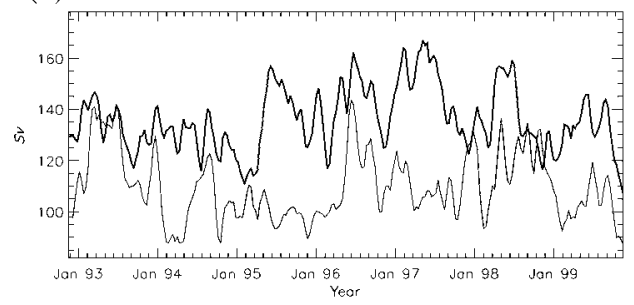

(b)

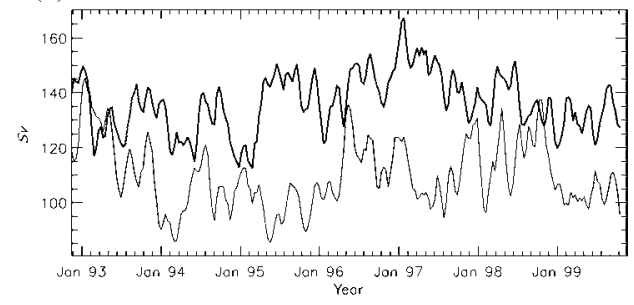

Figure 9. Time series of the Gulf Stream transport, averaged between $75^{\circ} \mathrm{W}$ and $65^{\circ} \mathrm{W}$ (thin curve), and between $65^{\circ} \mathrm{W}$ and $50^{\circ} \mathrm{W}$ (thick curve): (a) the original time series; $(b)$ the time series after removing the mean annual cycle. 


\subsection{Relationship between transport and position variations}

Several studies have examined the question of the correlation between the GS transport and position variations. Kelly et al. (1999) found a surface transport minimum in the spring coinciding with a southerly position, but Manning and Watts (1989) found a total transport maximum in the spring coinciding with a southerly position. Here, no correlation was found, even when a time lag is taken into account. Indeed, the transport exhibits a semi-annual periodicity, while the annual cycle of the GS latitudinal position is unimodal.

To our knowledge, no earlier study has evidenced correlation between position and transport at inter-annual time scales. We explored this type of correlation on the seven-year de-seasonalized time series in which the effect of the annual cycle is removed. Intuitive comparisons of the time series may suggest that inter-annual fluctuations of the transport and position could be in opposite phase. However, no significant correlations were found.

\section{Conclusion}

In this study, we have explored, by means of simple synthetic diagnostics (averaging) and more refined analyses (EOF), the spatial and temporal variability of the GS path between $75^{\circ} \mathrm{W}$ and $50^{\circ} \mathrm{W}$. We chose to divide the study into two areas, on either side of $65^{\circ} \mathrm{W}$. At the same time, we have studied the transport of the current towards the east.

With regard to position, the convergence of diagnostics made from the SSH and temperature fields at $200 \mathrm{~m}$ reinforces the reliability of our results, and enables us to confirm the coherent displacement of position along the vertical. The distinction made between the upstream and downstream zones enables us to identify two different behaviours for the position on either side of $65^{\circ} \mathrm{W}$. Upstream, the position exhibits marked inter-annual variability, which dominates the less visible annual variability. Downstream, annual variability is very regular and of greater amplitude than upstream. Over the domain as a whole, the observed seasonality agrees with the observations of Lee and Cornillon (1995), based on SST observations, but differs from the analysis of Frankignoul et al. (2001) using in situ temperature and altimetry. Unlike the findings of Kelly et al. (1999), the maximum annual signal is observed downstream and the upstream annual signal is weak.

Variability in transport appears more complex than that relating to position. Transport to the east observed along the course of the GS shows significant intraannual, inter-annual and annual variations. A noticeable feature is the semi-annual periodicity evidenced in both regions. On average, the strength of the flow is maximum in June-July and January, and minimum in November and March. The coherence of variations over the domain, observed for the position of the GS, cannot be evidenced for GS transport. This is true for both the time series with a 10day time step and for the low-pass filtered series. Finally, the common point for transport and position is the dominance of seasonality downstream.

\section{Acknowledgments}

This research was supported by Centre National d'Etudes Spatiales and the MERCATOR Project. We would like to thank Jean-Michel Brankart for fruitful discussions and for his help in dealing with the SESAM assimilation software. The calculations were conducted with the support of IDRIS/CNRS. 


\section{References}

Brasseur, P., Blayo, E. and Verron, J., 1996, Predictability experiments in the North Atlantic Ocean: outcome of a quasi-geostrophic model with assimilation of TOPEX/POSEIDON altimeter data. Journal of Geophysical Research, 101, pp. $14161-14173$.

Cornillon, P., 1986, The effect of the New England seamounts on Gulf Stream meandering as observed from satellite IR imagery. Journal of Physical Oceanography, 16, pp. 386-389.

EzER, T., 1994, On the interaction between the Gulf Stream and the New England Seamounts Chain. Journal of Physical Oceanography, 99, pp. 191-204.

Frankignoul, C., De Coetlogon, G., Joyce, T.M. and Dong, S.F., 2001, Gulf Stream variability and ocean atmosphere interactions. Journal of Physical Oceanography, 31, pp. 3516-3529.

Fu, L.L., VAzQuez, J. and PARke, M.E., 1987, Seasonal variability of the Gulf Stream from satellite altimetry. Journal of Geophysical Research, 92, pp. 749-754.

Hall, M.M. and FofonofF, N.P., 1993, Downstream development of the Gulf Stream from $68^{\circ}$ to $55^{\circ}$ W. Journal of Physical Oceanography, 23, pp. 225-249.

HENDRY, R.M., 1988, A simple model of the Gulf Stream thermal structure with application to analysis of moored measurements in the presence of mooring motion. Journal of Atmospheric and Oceanic Technology, 5, pp. 328-339.

HoGG, N.G., 1992, On the transport of the Gulf Stream between Cape Hatteras and the Grand Banks. Deep-Sea Research, 39, pp. 1231-1246.

Holland, W.R. and Lin, L.B., 1975, On the generation of mesoscale eddies and their contribution to the oceanic general circulation. I. A preliminary numerical experiment. Journal of Physical Oceanography, 5, pp. 642-657.

Johns, W., Shay, T., BAne, J. and WatTs, D., 1995, Gulf Stream structure, transport, and recirculation near $68^{\circ}$ W. Journal of Geophysical Research, 100, pp. 817-838.

Käse, R. and Krauss, W., 1996, The Gulf Stream, the North Atlantic Current, and the Origin of the Azores Current in the Warm Watersphere of the North Atlantic Ocean, W. Krauss (Ed.), pp. 291-337 (Berlin, Stuttgart: Gebrüder Borntraeger).

Kelly, K.A., 1991, The meandering Gulf Stream as seen by the Geosat altimeter: surface transport, position and velocity variance from 73 to $46^{\circ} \mathrm{W}$. Journal of Geophysical Research, 96, pp. 16721-16738.

Kelly, K.A. and Gille, S.T., 1990, Gulf Stream surface transport and statistics at $69^{\circ} \mathrm{W}$ from the Geosat altimeter. Journal of Geophysical Research, 95, pp. 3149-3161.

Kelly, K.A., Singh, S. and HuAng, R.X., 1999, Seasonal variations of sea surface height in the Gulf Stream region. Journal of Physical Oceanography, 29, pp. 313-327.

Leaman, K., Johns, E. and Rossby, T., 1989, The average distribution of volume transport and potential vorticity with temperature at three sections across the Gulf Stream. Journal of Physical Oceanography, 19, pp. 36-51.

LeE, T. and CoRnillon, P., 1995, Temporal variations of meandering intensity and domainwide lateral oscillations of the Gulf Stream. Journal of Geophysical Research, 100, pp. $13603-13613$.

Madec, G., Delecluse, P., Imbard, M. and Levy, C., 1998, OPA8.1 Ocean General Circulation Model Reference manual. Notes du pôle de modélisation, Technical Report, Institut Pierre-Simon Laplace (IPSL).

Manning, J. and WatTs, D., 1989, Temperature and velocity structure of the Gulf Stream northeast of Cape Hatteras: modes of variability. Journal of Geophysical Research, 94, pp. 4879-4890.

Pham, D., Verron, J. and Roubaud, M., 1998, A Singular Evolutive Extended Kalman filter for data assimilation in oceanography. Journal of Marine Systems, 16(3-4), pp. 323-340.

RichARDSON, P., 1981, Gulf Stream trajectories measured with free-drifting buoys. Journal of Physical Oceanography, 11, pp. 999-1009. 
Rossby, T. and Benway, R.L., 2000, Slow variations in mean path of the Gulf Stream east of Cape Hatteras. Geophysical Research Letters, 27, pp. 117-120.

SAto, O.T. and Rossby, T., 1995, Seasonal and low frequency variations in dynamic height anomaly and transport of the Gulf Stream. Deep-Sea Research, 42, pp. 149-164.

Sturges, W. and Hong, B., 2001, Gulf Stream transport variability at periods of decades. Journal of Physical Oceanography, 31, pp. 324-332.

Taylor, A. and Stephens, J., 1998, The North Atlantic Oscillation and the latitude of the Gulf Stream. Tellus, 50A, pp. 134-145.

Testut, C.-E., Brasseur, P., Brankart, J.-M. and Verron, J., 2003, Assimilation of seasurface temperature and altimetric observations during 1992-1993 into an eddypermitting primitive equation model of the North Atlantic Ocean. Journal of Marine Systems, 40-41, pp. 291-316.

Visbeck, M., Chassignet, E., Curry, R., Delworth, T., Dickson, B. and Krahmann, G., 2003, The ocean's response to North Atlantic Oscillation variability. In The North Atlantic Oscillation, J.W. Hurrell, Y. Kushnir, G. Ottersen and M. Visbeck (Eds) Geophysical Monograph Series, 134, pp. 113-146.

Zlotnicki, V., 1991, Sea level differences across the Gulf Stream and Kuroshio extension. Journal of Physical Oceanography, 21, pp. 599-610. 